\title{
Flexibility and assembly of viral capsids*
}

\author{
M. F. THORPE
}

Departments of Physics \& Astronomy and Department of Chemistry and Biochemistry, Arizona State University, USA

We present a novel approach to the calculation of flexibility and mobility in proteins, protein complexes and other large macromolecular complexes like virus capsids. Rather than using conventional molecular dynamics, we use the constraint approach of Lagrange, incorporating covalent bonds, hydrogen bonds and tethers for hydrophobic interactions. The rigid clusters, including the core, as well as the flexible joints between them are identified. Subsequently, this can be used as the basis for dynamics, using Monte Carlo approaches that maintain all the original constraints, as well as van der Waals excluded volumes.

In our original work [1,2], we focused on ring closure and added the side groups later. This was successful in exploring the available conformational space and also in exploring directed trajectories between known distinct protein structures.

We show that such techniques can be used on a single $\mathrm{X}$-ray crystallographic structure to generate an ensemble of structures remarkably similar to those observed in NMR [2]. We also show how this approach can be used to generate multiple protein complexes for use in ligand docking studies, as well as exploring the allowed conformations of protein-ligand complexes.

This approach, applied at the atomic level, can handle macromolecular assemblies of up to a million atoms, to determine the rigid regions and the flexible joints between them. An application of this approach to the stability and assembly of an icosahedral viral capsid and cowpea chlorotic mottle virus are discussed [3].

\section{References}

[1] Jacobs, D.J., Rader, A.J., Kuhn, L.A. and Thorpe, M.F., 2001, Protein flexibilty predictions using graph theory. Proteins, 44, 150-165.

[2] Lei, M., Kuhn, L.A., Zavodszky, M.I. and Thorpe, M.F., 2004, Sampling protein conformations and pathways. J. Comput. Chem., 25, $1133-1148$.

[3] Hespenheide, B. M., Jacobs, D.J. and Thorpe, M.F., 2004, Structural rigidity in the capsid assembly of cowpea chlorotic mottle virus. J. Phys.: Condens. Matter, 16, S5055-S5064.

[4] Zavodszky, M.I., Lei, M., Thorpe, M.F., Day, A.R. and Kuhn, L.A., 2004, Modeling correlated main-chain motions in proteins for flexible molecular recognition. Proteins: Struct., Funct. and Bioinformatics, 57, 243-261.

*Work supported by NSF and NIH. 


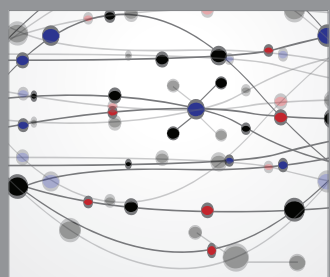

The Scientific World Journal
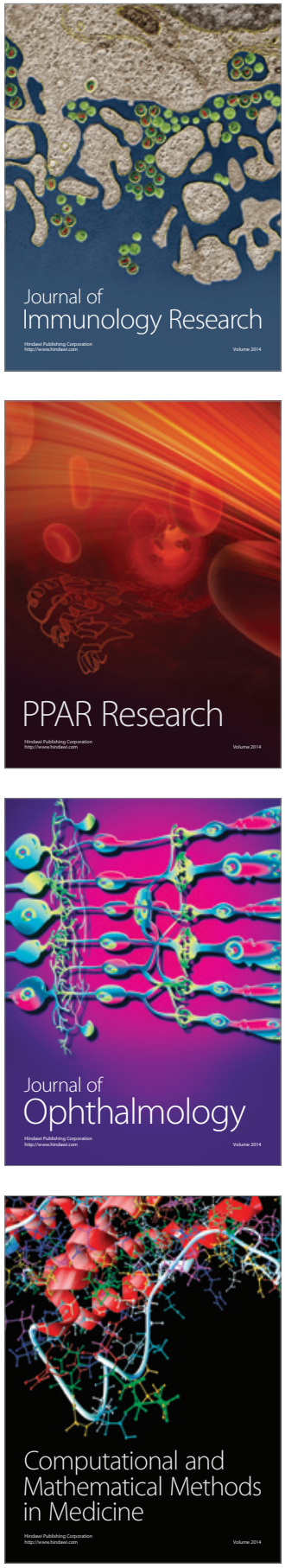

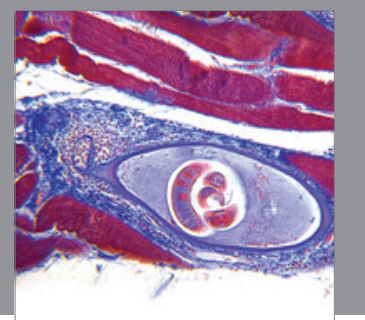

Gastroenterology

Research and Practice
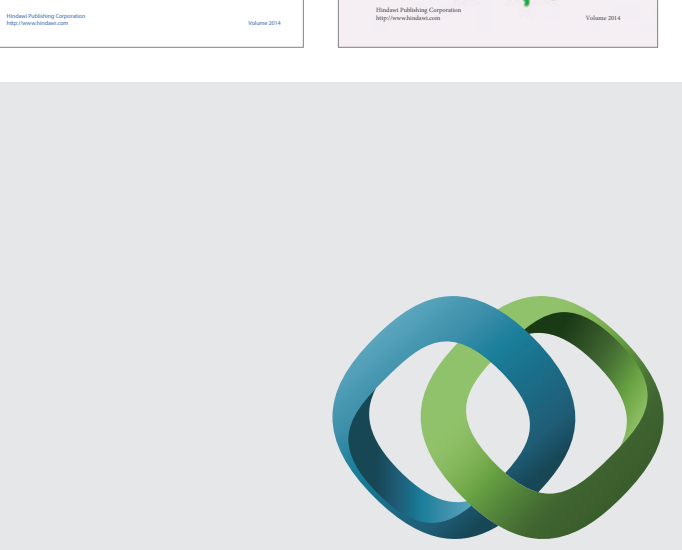

\section{Hindawi}

Submit your manuscripts at

http://www.hindawi.com
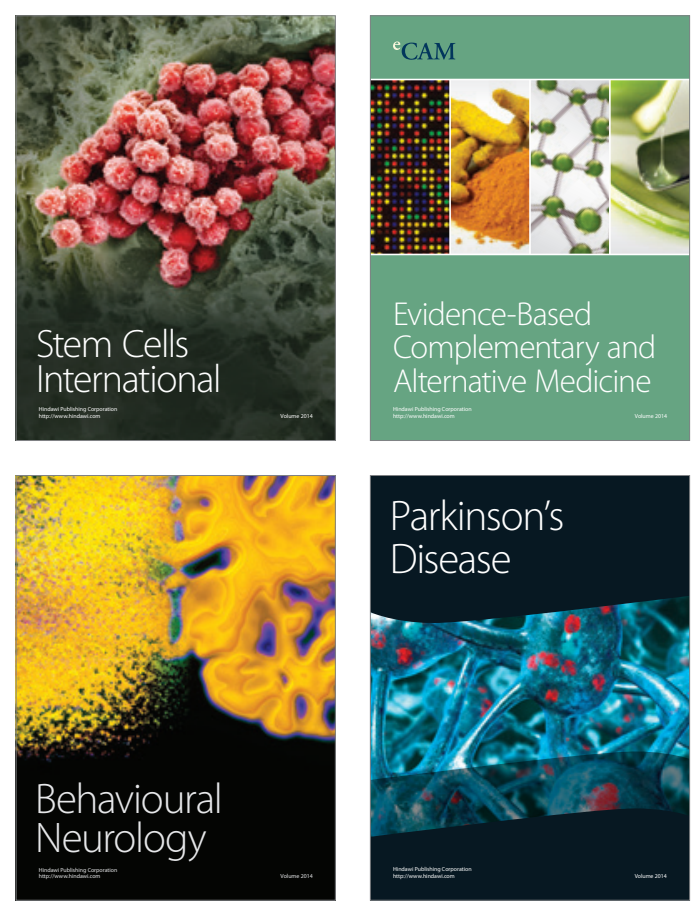

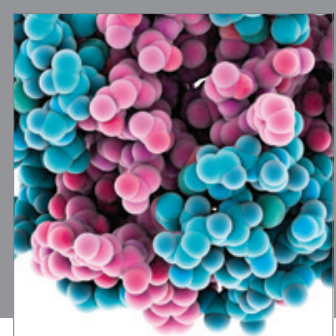

Journal of
Diabetes Research

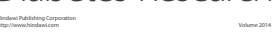

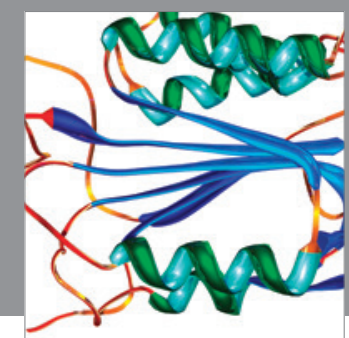

Disease Markers
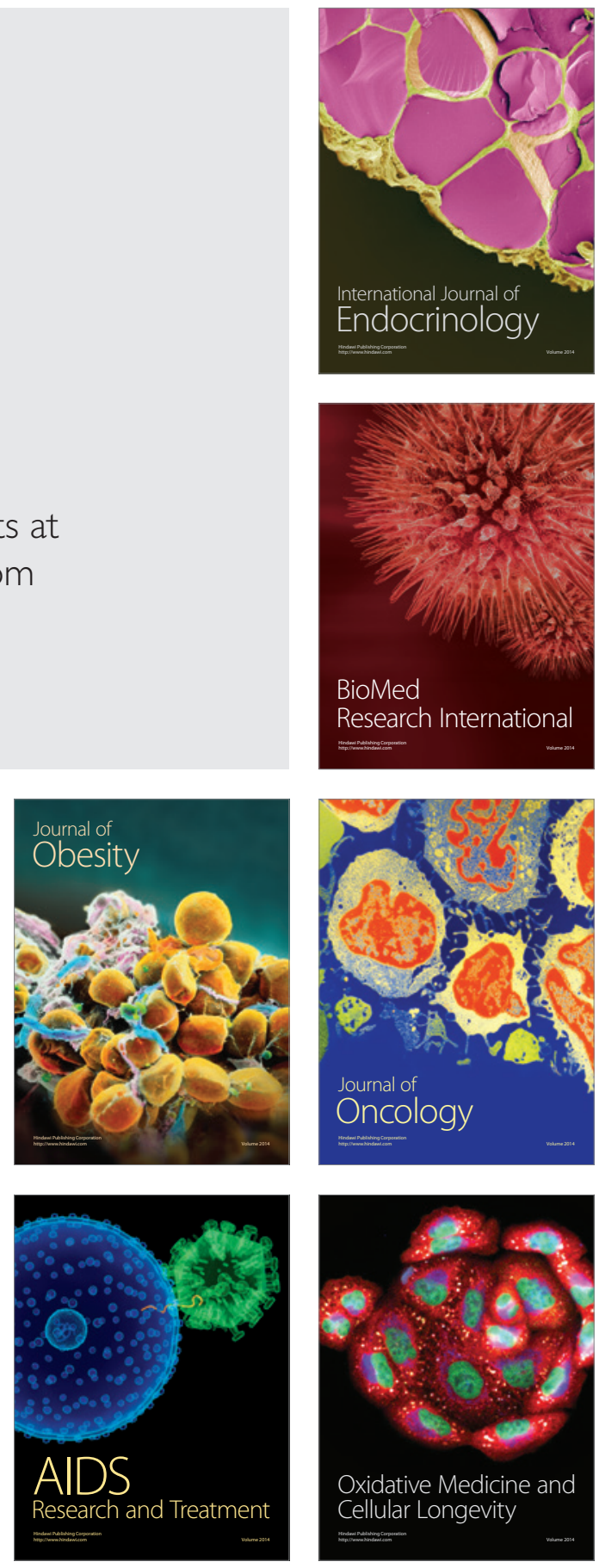